\title{
Environmental and nutritional analysis of the EAT-Lancet diet at the individual level:
}

\section{insights from the NutriNet-Santé study}

Emmanuelle Kesse-Guyot ${ }^{1 *}$, Pauline Rebouillat ${ }^{1}$, Joséphine Brunin ${ }^{1}$, Brigitte Langevin ${ }^{2}$, Benjamin Allès ${ }^{1}$,

Mathilde Touvier ${ }^{1}$, Serge Hercberg ${ }^{1,3}$, Hélène Fouillet ${ }^{5}$, Jean-François Huneau ${ }^{5}$, François Mariotti ${ }^{5}$, Denis

Lairon $^{4}$, Philippe Pointereau ${ }^{2}$, Julia Baudry ${ }^{1}$

\section{Affiliations:}

${ }^{1}$ Sorbonne Paris Nord University, Inserm, Inrae, Cnam, Nutritional Epidemiology Research Team

(EREN), Epidemiology and Statistics Research Center - University of Paris (CRESS), 93017 Bobigny,

France

${ }^{2}$ Solagro, Toulouse, France

${ }^{3}$ Public Heath Department, Avicenne Hospital, AP-HP, 93017 Bobigny, France

${ }^{4}$ Human nutrition, Aix Marseille Université, INSERM, INRAE, C2VN, Marseille, France

${ }^{5}$ Université Paris-Saclay, AgroParisTech, INRAE, UMR PNCA, 75005, Paris, France

*Corresponding author:

Emmanuelle Kesse, $\mathrm{PhD}$

Equipe de Recherche en Epidémiologie Nutritionnelle (EREN)-Université Sorbonne Paris Nord, SMBH -

74 rue Marcel Cachin-93017 Bobigny France

Phone number: + 33148388979

e.kesse@eren.smbh.univ-paris13.fr

Running Head: planetary health diet and environmental impacts

ELD-I;

\section{Number of tables/figures: $4 / 2$}

Abbreviations:

ANCOVA: covariance analysis

BMI: body mass index

Cumulative energy demand: CED 
CU: consumption units

EAT-Lancet Diet Index: ELD-I

FBDGs: food-based dietary guidelines

Food frequency questionnaire: FFQ

Greenhouse gas emissions: GHGe

HR : hazard ratio

Land occupation: LO

PNNS-GS, Programme National Nutrition Santé-Guideline Score

PNNS-GS2: Programme National Nutrition Santé-Guideline Score 2

Q: quintile 


\section{Abstract}

1 The EAT-Lancet Commission has recently proposed a "universal" healthy reference diet. However, no

2 study has specifically investigated its possible environmental benefits at the individual level based on

3 observed data. Our objective was therefore to characterize the environmental pressures and impacts

4 related to the level of adherence to the EAT-Lancet diet among French adults. Dietary data from a 264-

5 item FFQ in 29,210 NutriNet-Santé participants ( $75 \%$ women, mean age $=53.5 \mathrm{y}(\mathrm{SD}=14.0)$ ), were used to

6 estimate (i) the level of adherence to the EAT-Lancet diet through the EAT-Lancet diet index (ELD-I), (ii)

7 the food production-related environmental impacts using 3 individual environmental indicators

8 (greenhouse gas emissions, cumulative energy demand and land occupation) and (iii) the overall

9 environmental impact using a validated aggregated partial score ( $p \mathrm{ReCiPe})$. For clarity purpose, results are

10 presented by quintile (Q) of ELD-I. High ELD-I ( $\left.\mathrm{Q}_{5}\right)$, compared to low $\left(\mathrm{Q}_{1}\right)$, was associated with lower

11 greenhouse gas emissions (-56\%), cumulative energy demand (-31\%) and land occupation, (-54\%). The

$12 p$ RECIPE was $62 \%$ lower in high ELD-I than in low ELD-I but the range of pReCiPe in Q1 was large. In

13 this large scale-study of French adults, adherence to the EAT-Lancet recommendations led to lower

14 environmental impacts. Nonetheless, some low-EAT diets (reflecting unhealthy diets), may exhibit low

15 environmental impacts.

16 Keywords: environmental impacts; dietary patterns; cohort study; EAT-Lancet diet 


\section{Highlights}

- the EAT-Lancet diet index was developed to assess the EAT-Lancet diet adherence while accounting for farming practices (organic or conventional).

- The diets highly correlated with the EAT-Lancet diet (compared to low adherence) led to lower impacts: $-56 \%$ greenhouse gas emissions, $-31 \%$ cumulative energy demand and $-54 \%$ land occupation.

- A high variability in environmental impacts was observed among individuals with low adherence to the EAT-Lancet diet, reflecting a discrepancy between human and planetary health. 


\section{Introduction}

24 It is now well established that modern eating habits, rich in fat, salt and sugar, largely contribute to the 25 development of chronic diseases (GBD 2017 Diet Collaborators, 2019). In 2017, the Global Burden of

26 Diseases estimated that 11 million (95\% uncertainty interval 10-12) deaths were attributable to diet-related

27 risk factors (GBD 2017 Diet Collaborators, 2019). Besides, diet production cause serious damages and long-

28 term adverse effects on the environment. Indeed, the climate crisis, the depletion of natural resources and

29 the pollution of water and soil require a radical and urgent change at multiple levels of the global food

30 system, from field to plate (Clark et al., 2018). In case of no drastic change in the food system by 2050,

31 greenhouse gas emissions (GHGe), land use, water use, as well as nitrogen and phosphorus application

32 would drive natural processes beyond planetary limits (Springmann et al., 2018).

33 A growing body of evidence documents that diets largely based on plant foods with limited amount of 34 animal products could bring benefits to the environment (Lukasz Aleksandrowicz et al., 2016; Auestad and 35 Fulgoni, 2015; Chai et al., 2019). Specifically, vegetarian and vegan diets have been consistently associated with lower environmental impacts compared to meat-based diets (Chai et al., 2019). This is in line with findings from modeling studies aiming at determining environmental-friendly diets (Gazan et al., 2018; van Dooren, 2018). Besides, other studies have evaluated different types of diet such as the Mediterranean diet, the Nordic diet or adherence to several dietary guidelines (Lukasz Aleksandrowicz et al., 2016; Auestad and Fulgoni, 2015; Chai et al., 2019; Ridoutt et al., 2017). All these findings consistently documented environmental impacts of cropland and livestock (Clark et al., 2019). Livestock, in particular beef, is responsible for a large part of the dietary-related GHGe and also leads to deforestation and loss of

43 biodiversity (Gerber et al., 2013). With regard to health aspects, other protein sources need to be favored, 44 while meat - in particular red and processed meat - consumption should be reduced, given the positive link 45 between meat consumption and numerous chronic diseases (cancer, cardiovascular diseases, type 2 diabetes 46 as well as overall mortality) (GBD 2017 Diet Collaborators, 2019; Mariotti, 2019).

47 In that context, in 2019, the EAT-Lancet commission proposed a universal healthy diet. The evidence-based EAT-Lancet diet, aligning nutrition with planet preservation, is the first global reference diet that could 
49 allow a sustainable trajectory within the planetary boundaries. It provides an anchor point for future national

50 food policies across culturally diverse countries by enabling them to incorporate environmental preservation

51 into their national food-based dietary guidelines (FBDGs). It is also designed to serve as a reference for

52 "estimating health and environmental effects of adopting an alternative diet to standard current diets (Willett

53 et al., 2019). This diet is based on the available scientific literature on the relationships between food intake

54 and health. The EAT Lancet Commission concluded that "a dietary change towards increased adoption of

55 plant-based diets has high mitigation potential, which is probably needed to limit global warming to a less

56 than $2^{\circ} \mathrm{C}$ increase" (Willett et al., 2019). The EAT-Lancet diet is a $2500 \mathrm{kcal}$ daily diet which promotes

57 plant food consumption such as whole grains, fruit and vegetables, legumes and drastically limits the intake

58 of added fat and sugars as well as animal food such as beef, lamb, pork - and to a lesser extent fish, eggs

59 and chicken. A recent study documented nutritional comparison between the EAT-Lancet diet and Dietary

60 Guidelines for American and identified some discrepancies for some plant-based food groups that were

61 more encouraged in the EAT-Lancet such as soy-based food, nuts and seeds and whole grain starch

62 (Blackstone and Conrad, 2020). Besides, the EAT-Lancet report has generated controversies with studies

63 documenting null (Zagmutt et al., 2020) or protective association as regards the risk of ischemic heart

64 diseases, diabetes and mortality (Knuppel et al., 2019), while another study put into question its affordability

65 for the world's poor (Hirvonen et al., 2020). A recent modelling study however indicates that the EAT-

66 Lancet recommendations were more in line with the World agenda on health and sustainability than most

67 national FBDG (Springmann et al., 2020). However, no study has explored environmental impact of

68 adherence to the EAT-Lancet diet. Thus, the translation of the EAT-Lancet recommendations at the

69 individual level and in various cultural settings is necessary to thoroughly characterize the sustainability of

70 the EAT-Lancet diet and in particular environmental dimension.

71 Most studies exploring the associations between environmental pressures and dietary patterns have used a

72 small range of indicators, mainly GHGe and land use (Jones et al., 2016). Besides, few studies have

73 considered overall impact indicators whereas this would allow to include several pressure indicators, and

74 thus to address trade-offs between the different environmental footprints (Kramer et al., 2017). In addition, 
studies have mainly considered the dominant intensive system in their assessment while agroecological systems might differ on some indicators (Gomiero et al., 2011). The use of the organic farming system as an alternative model is therefore of interest, especially since it has been shown that occidental individuals who eat a lot of plant foods also eat more organically-grown products (Lacour et al., 2018).

In the present work, we therefore aimed to explore the link between adherence to the EAT-Lancet diet and associated environmental impacts considering 3 indicator of pressure and 1 impact while considering farming practices for food production. A first dietary index based on binary components has been developed to reflect the adherence to the EAT-Lancet diet in the EPIC-Oxford study (Knuppel et al., 2019). However, this index does not account for variability in consumption, we thus, chose to develop a new continuous index to better apprehend variability in consumption.

\section{Material and methods}

\subsection{Population}

These analyses were based on the NutriNet-Santé study (registered at clinicaltrials.gov as NCT03335644). NutriNet-Santé is a prospective cohort study implemented in 2009 to investigate the links between food, its determinants and health (Hercberg et al., 2010). Participants are volunteers recruited through a media campaign and who complete regular online questionnaires. At inclusion and each year thereafter, they provided data on their health, their practices (diet, lifestyles) and their socio-demographic characteristics.

This study was conducted in accordance with the Declaration of Helsinki, and all procedures were approved by the Institutional Review Board of the French Institute for Health and Medical Research (IRB Inserm 0000388FWA00005831) and the National Commission on Informatics and Liberty (Commission Nationale de l'Informatique et des Libertés, CNIL 908450 and 909216). Electronic informed consent was obtained from all participants.

Data used in this work have been described elsewhere (Kesse-Guyot et al., 2020).

\subsection{Dietary data}

In 2014, a web-based semi-quantitative food frequency questionnaire (FFQ) (Kesse-Guyot et al., 2010) was proposed to the volunteers. They were asked to report their frequency of consumption of 264 food items, as 
100

101

102

103

104

105

well as the portion consumed with photographs helping for the identification of portion size. In addition in this modified version of the FFQ (Baudry et al., 2015), for each food item, participants declared the frequency with which the item was organic through the following modalities never, rarely, half of the time, most of the time, always. Weights $(0,0.25,0.5,0.75,1)$ were allocated to the consumption to split the total consumption of each item into organic and conventional sources. Further details and sensitivity analyses related to computation have been published elsewhere (Baudry et al., 2015). Nutrient intakes were computed using a published composition table and under/over-reporters were excluded as previously described using percentiles of the ratio between energy intake and energy requirement (Baudry et al., 2015). Bioavailable zinc and iron were computed using published equation (Armah et al., 2013; Miller et al., 2007).

\subsection{EAT-Lancet diet index (ELD-I)}

Based on the definition of the universal healthy diet (Willett et al., 2019), component and cut-off of the EAT-Lancet diet have been already proposed in a previous work (Knuppel et al., 2019), regarding the following 14 food groups: whole grains, tubers and starchy vegetables, vegetables, fruits, dairy foods, beef/lamb/pork, chicken and other poultry, eggs, fish, legumes, nuts, saturated oil, unsaturated oils and sweeteners. Cutoffs for each component are presented in Table 1. For sweeteners component, intake of added sugars was used. To improve the power of discrimination of the dietary index reflecting the adherence to the EAT-Lancet diet, compared to the previously developed score (Knuppel et al., 2019), we accounted for deviation from the cut-off value. The EAT-Lancet diet index (ELD-I) for an individual $j$ with intake for each $i$ was computed as follows, equation (1):

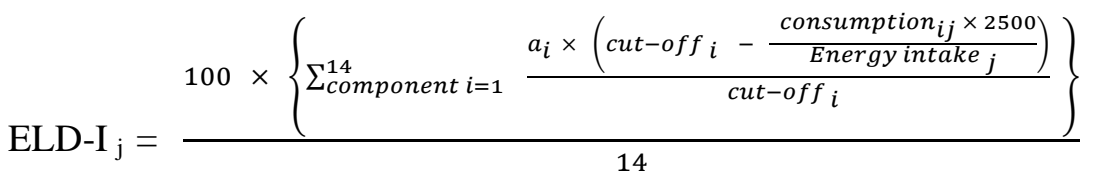

Where $i$ referred to on the 14 food groups and $\mathrm{j}$ is the individual. $a_{i}=1$ for component to limit and $a_{i}=-1$ for component to promote.

\subsection{Environmental data}


123 Three environmental indicators were computed, namely greenhouse gas emissions (GHGe), cumulative

124 energy demand (CED), and land occupation (LO) whose computation has been extensively described

125 elsewhere (Baudry et al., 2019). These impacts were considered at the farm level, i.e. without considering

126 post-harvest storage, conditioning and transport since these data were not available for organic farming. It

127 should be however noted that most of the environmental impacts take place during the agricultural

128 production phase (Clune et al., 2017). Data were derived from the DIALECTE tool (Pointereau et al., 2012)

129 developed by Solagro (Toulouse, France) aiming to measure the environmental performance of 130 conventional and organic farms. Data were completed using other data sources (Baudry et al., 2019).

131 Environmental impacts of 92 conventional and organic raw products were assessed and converted into food 132 items using economic, cooking and edibility coefficients (Baudry et al., 2019). Environmental data related 133 to raw products for both organic and conventional farming have been previously disclosed (Baudry et al., 134 2019). Procedures for environmental estimation is summarized on Figure 1.

135 Intake and related environmental impacts were compiled for each food and then summed up considering 136 organic and conventional systems to compute daily environmental indicator at the diet level.

137 To provide a synthetic index of available indicators in our study, we used the partial ReCiPe index, based 138 on the ReCiPe method, a synthetic environmental impact indicator (Kramer et al., 2017).

139 The $p$ ReCiPe was calculated for each individual as follows, equation (2):

$$
p R e C i P e=0.0459 \times G H G e+0.0025 \times C E D+0.0439 \times L O
$$

141 with GHGe, in $\mathrm{kg}$ of $\mathrm{CO}_{2} \mathrm{eq} / \mathrm{d}, \mathrm{CED}$, in $\mathrm{MJ} / \mathrm{d}$ and $\mathrm{LO}$, in $\mathrm{m}^{2} / \mathrm{d}$. The highest the $\mathrm{pReCiPe}$, the highest the 142 environmental impact.

\section{$143 \quad 2.5$ Other data}

144 As complementary approaches to the planetary health diet, we computed two scores: the PANDiet and the 145 health gain score.

146 The PANDiet aims at estimating the probability of adequacy of nutrient intakes (Gavelle et al., 2018). This

147 score includes an adequacy sub-score (averaging the probabilities of adequacy for 27 nutrients) and a 
moderation sub-score including 6 nutrients and 12 penalty values referring to the probabilities of exceeding upper limits of intakes as showed on the Figure 2.

The health gain score (HS) proposed by Van Dooren et al. (van Dooren et al., 2014) is a synthetic score designed to measure health benefits of diets. It includes 10 components, as trans fatty acids were not available in our database, we therefore adapted it as follows, equation (3):

$\mathrm{HS}=\left[\left(\frac{\text { vegetables }}{200}\right)+\left(\frac{\text { fruits }}{200}\right)+\left(\frac{\text { fiber }}{40}\right)+\left(\frac{\text { fish }}{37}\right)+\left(\frac{6}{\text { salt }}\right)+\left(\frac{30}{\% \text { EI total fat }}\right)+\left(\frac{10}{\% \text { EI SFA }}\right)+\left(\frac{10}{\% \text { EI free sugars }}\right)+\right.$ $\left.\left(\frac{2500}{\text { EI }}\right)\right] \times \frac{100}{9}$

where consumptions are in grams, EI denotes energy intake in kcal, and SFA denotes saturated fatty acids. Sociodemographics (gender, age, education, professional categories, monthly incomes, household composition), lifestyle data (smoking status, physical activity), anthropometrics (height and weight) were collected using follow-up questionnaires (Kesse-Guyot et al., 2016). Monthly household income was calculated per consumption unit using the following weighting ("Définition - Unité de consommation | Insee," n.d.): 1 consumption unit (CU) is attributed for the first adult in the household, $0.5 \mathrm{CU}$ for other persons aged $\geq 14 \mathrm{y}$, and $0.3 \mathrm{CU}$ for children aged $<14 \mathrm{y}$. Physical activity was assessed using a short form of the French version of the International Physical Activity Questionnaire (Hagstromer et al., 2006) and classified as low physical activity ( $<30$ min of physical activity equivalent to brisk walking/d), moderate physical activity ( $\geq 30$ and $<60 \mathrm{~min}$ ), or high physical activity ( $\geq 60 \mathrm{~min}$ ), according to the French guidelines. BMI was calculated as the ratio of weight to squared height $\left(\mathrm{kg} / \mathrm{m}^{2}\right)$. The data closest to the FFQ were retained.

Place of food purchase and prices were combined with consumption to estimate the daily cost of the diet. Briefly, a database of prices by place of purchase was developed using the Kantar database (Kantar Worldpanel, n.d.), involving 20,000 French households, and further completed with collected prices for short supply chains which are not available in Kantar. This procedure has been extensively described elsewhere (Baudry et al., 2019; Seconda et al., 2018).

\subsection{Statistical analysis}


173 For the present study, we selected the NutriNet-Santé participants who had completed the Org-FFQ in 2014

$174(\mathrm{~N}=37,685)$, with no missing covariates for weight and height $(\mathrm{N}=37,305)$, not detected as under- or over-

175 energy reporter $(\mathrm{N}=35,196)$. Next, we selected participants with available data for computation of the cost

176 of the $\operatorname{diet}(\mathrm{N}=29,210)$.

177 Participants were ranked and categorized into quintiles (Q) of ELD-I reflecting the level of adherence.

178 Associations between sociodemographics, cost of the diet, food group consumption, nutritional and

179 environmental indicators and quintiles of the ELD-I were assessed with ANCOVA using observed margins.

180 Differences across quintiles were estimated providing the means and the confidence intervals of the mean.

181 For environmental indicators, additional models adjusted on energy intake were performed. For statistical 182 tests, the type I error was set at 5\%. Data management and statistical analyses were conducted using SAS ${ }^{\circledR}$

1839.4 (SAS Institute Inc.) and graphics were performed using $\mathrm{R}^{\circledR}$ (version 3.4.2).

\section{Results}

184 3.1. Relationship between adherence to the EAT-Lancet diet and socio-economic characteristics of 185 participants

186 The characteristics of the sample according to the quintiles of the ELD-I are presented in Table 2. Compared 187 to participants with lower ELD-I, participants with higher ELD-I were less frequently men ( $\mathrm{Q}_{5}$ vs. $\mathrm{Q}_{1}$, $34.51 \%$ vs. $62.20 \%$ ), older (mean age about $+6 y$ ), less often postgraduate ( $\mathrm{Q}_{5}$ vs. $\mathrm{Q}_{1}, 19.14 \%$ vs. $25.26 \%$ ),

189 less often employee or manual worker ( $\mathrm{Q}_{5}$ vs. $\mathrm{Q}_{1}, 26.36 \%$ vs. $\left.41.03 \%\right)$, and more often physically active 190 (Q $\mathrm{Q}_{5}$ vs. $\mathrm{Q}_{1}, 44.10 \%$ vs. $27.15 \%$ ) or with high income and had lower BMI (mean BMI about $-2 \mathrm{~kg} / \mathrm{m}^{2}$ ). In 191 addition, Participants with high adherence to the EAT-Lancet had the highest diet cost. However, the 192 association appeared to be J-shaped.

193 3.2. Relationship between adherence to the EAT-Lancet diet and the nutritional characteristics of 194 the diet

195 Nutritional characteristics according to ELD-I quintiles are presented in Table 3. High ELD-I was 196 negatively associated with energy intake (Q $\mathrm{Q}_{5} \mathrm{vs} . \mathrm{Q}_{1}, 1935 \mathrm{kcal} / \mathrm{d} \mathrm{vs} .2099 \mathrm{kcal} / \mathrm{d}$ ), and positively with the 
health gain score as well as the PANDiet score (mean PANDiet about +11 ), proportion of organic food in the diet ( $\mathrm{Q}_{5}$ vs. $\mathrm{Q}_{1}, 0.45$ vs. 0.17), of polyunsaturated fatty acids, plant proteins, and intake of fibers, vitamin C, vitamin B9, vitamin E, total iron and bioavailable zinc. Participants with higher ELD-I also exhibited lower $\%$ of energy intake from saturated fatty acids and total proteins and lower intakes of sodium, zinc and heme-iron.

\subsection{Relationship between adherence to the EAT-Lancet diet and environmental impact indicators}

203 The three studied environmental indicators (CED, GHGe and LO) as well as the aggregated score $(p \mathrm{ReCiPe})$

204 across quintiles of ELD-I are presented in Table 4. Negative associations were observed between the ELD-

205 I (modeled as quintiles) and each environmental indicator, which were stronger for GHGe and LO than for 206 CED but showed in each occasion a dropout in the $5^{\text {th }}$ quintile. High EAT-LS $\left(\mathrm{Q}_{5}\right)$ compared to low $\left(\mathrm{Q}_{1}\right)$ 207 was associated with lower greenhouse gas emissions (-56\%), cumulative energy demand (-31\%) and land occupation (-54\%). As regards the $p$ ReCiPe index, a reduction of $63 \%$ was observed when comparing $\mathrm{Q}_{5}$ vs $\mathrm{Q}_{1}$. All associations were linear $(\mathrm{p}<0.0001)$.

210 Further adjustment for energy intake did not strongly modify the association (for $p$ ReCiPe index: $-62 \%$ ).

211 The distributions of the pReCiPe across ELD-I quintiles are shown in Figure 3. Figure 4 showed that despite

212 a statistically significant lowering values across quintiles, a great variability occurs, especially in the $1^{\text {st }}$

213 quintile. Similar findings were showed for individual environmental indicators constituting the pReCiPe

214 (data not shown). Pearson correlation coefficient between the ELD-I and the $p$ ReCiPe was -0.59.

215 Food consumption (standardized for $2500 \mathrm{Kcal}$ ) by quintiles are presented in Figure 4. As consumption 216 were almost zero, unsaturated oil consumption was not represented. Gradients across quintiles were 217 expected by construction. However, the most stringent differences between quintiles were for fruits and 218 vegetables and legumes. We can note that fish consumption appeared to be relatively similar across quintiles 219 but a little weaker in the $5^{\text {th }}$ quintile.

\section{Discussion}

220 In the present analysis, conducted in a large cohort of French adults, we explored, using detailed 
"Universal" healthy plant-based diet as defined by the EAT-Lancet Commission (Willett et al., 2019). We showed that a higher adherence to the EAT-Lancet diet, using an individual dietary score accounting for distance to cut-offs value for each component, was markedly related to a better nutritional diet quality (higher PANDiet score). It is noteworthy that a high ELD-I was associated with a slightly lower bioavailable iron intake. However, the mean value for individuals in the $5^{\text {th }}$ quintile remained higher than the estimated average losses (Hunt et al., 2009). In addition, micronutrients found in meat (such as zinc and vitamin B12) were not particularly low. As expected, fiber intake, which has been associated with lower risk of cancer, cardiovascular diseases, type 2 diabetes and mortality (Veronese et al., 2018), was high among participants with high ELD-I. Besides, plant proteins were high but ratio between plant to total protein reached $48 \%$ only. This may be directly due to the developed methodology as the score was based on probability rather than a threshold to be reached. The overall health gain score (related to nutrient intakes) was 55\% higher in participants with high ELD-I compared to those with low ELD-I, arguing for a latent alignment between environmental and nutritional dimensions of the "planetary health diet".

Dietary patterns of participants in $\mathrm{Q}_{5}$ were close to vegetarian dietary patterns, though animal products, especially meat, were not totally excluded from $\mathrm{Q}_{5}$ participants' diets. This was illustrated by an increase in the PANDiet score across quintiles despite a reduced animal-food consumption. Dietary pattern in $\mathrm{Q}_{5}$ of the ELD-I directly compared to the $\mathrm{Q}_{5}$ of PNNS-GS2 reflecting French food-based dietary guidelines (FBDG), which conceptually considered sustainability, after standardization for a $2500 \mathrm{kcal}$ diet, exhibited lower consumption in all food groups specifically, drastic lower consumption of meat (-36\%), eggs (-34\%), dairy product $(-33 \%)$, fat and sweet products $(-33 \%)$, as well as whole-grain (-34\%) (data not shown). This stemmed from the fact that participants with high adherence to French FBDG exhibited low energy intake. In turn, translation for $2500 \mathrm{kcal}$ led to higher levels of consumption (Kesse-Guyot et al., 2020). Another study, conducted in the US compared dietary guidelines for American (DAG) to EAT-Lancet diet (Blackstone and Conrad, 2020). The authors reported some consistencies between both diets but also divergences in particular concerning whole-grain starch, beans and peas and nuts, seeds and soy-based food 
247 leading to high increase in total proteins. This is in line with a global study reporting that most of national

248 FBDG were not compatible with environmental objectives (Springmann et al., 2020).

249 Adherence to the EAT-Lancet diet was strongly and negatively related to the three studied environmental 250 impacts, namely GHGe, CED and LO, as well as to the synthetic environmental index ( $p$ ReCiPe), allowing 251 to consider potential trade-offs. A reduction of $62 \%$ of the pReCiPe index between participants with high 252 vs low adherence to this diet was observed. This is consistent with the findings of the recent modelling study 253 by Springmann et al. documenting a reduction in the demand for environmental resources associated with 254 compliance with the EAT-Lancet diet (Springmann et al., 2020). We also showed that participants with high 255 adherence to the EAT-Lancet diet had a significantly higher consumption of organic food in their diet. As 256 previously shown, organic food consumption is positively associated with plant-based diet (Baudry et al., 257 2019; Lacour et al., 2018). Organic farming is an acknowledged agroecological production method that has 258 been shown to be a good proxy of diet-related biodiversity due to non-use of chemical pesticides (Tuomisto 259 et al., 2012) and is associated with reduced pesticides exposure from diet in our population (Baudry et al., 260 2018) and others (Mie et al., 2016).

261 Our results cannot be directly compared to scientific literature since, to the best of our knowledge, no study 262 has reported environmental values related to the EAT-Lancet diet at the individual level. Nevertheless, our 263 findings can be interpreted in light of findings about observed diets and dietary guidelines.

264 In France, diet is rather rich in animal products as it has been showed that comparing 4 other European 265 countries, French diet, based on the representative national study INCA-2 Study (2006-2007), exhibited the 266 highest values for land occupation and GHGe (Mertens et al., 2019). Besides, our findings are consistent 267 with the scientific literature which have consistently documented that plant-based diets are associated with 268 lower pressures on resources and environment in several observational or modelling studies (Springmann 269 et al., 2018; Chai et al., 2019; L. Aleksandrowicz et al., 2016; Clark et al., 2019; Hallström et al., 2015), in 270 line with the EAT Lancet Commission objectives. For instance, Hallström reported that changes in dietary 271 patterns (with more or less exclusion of animal products) may lead to an up to 50\% reduction in GHG 272 emissions and land use demand (Hallström et al., 2015). A recent study estimating the impacts of six US 
273 consumer diets considered the EAT-Lancet diet among various dietary patterns (Laroche et al., 2020). In

274 this work, the EAT-Lancet diet showed an intermediate land use, between the lacto-ovo-vegetarian and the

275 low-meat diets. Apart from an expected lower demand for land occupation, this study revealed that low-

276 meat diets rely more heavily on the abundance and diversity of pollinators and may increase impacts on

277 water resources at least in some countries. In addition, the Mediterranean Diet, permitting some animal food

278 (such as diary) consumption is often advanced as a sustainable diet (41). Indeed, one study documented a

279 higher GHGe $(+15 \%)$ and water use $(+9 \%)$ for a diet based on the Spanish dietary guidelines compared to

280 the Mediterranean diet (González-García et al., 2020). However, it has also been reported that

281 Mediterranean Diet had a global warming potential about twice that of the vegan diet (Castañé and Antón, 282 2017).

283 Also, a recent study was conducted to evaluate sustainability (using a synthetic score summarizing 4 284 environmental indicators) and to compare environmental performances of different dietary guidelines. The 285 authors showed that environmental values differed according to the diet, Nordic Diet being the most efficient 286 (Grosso et al., 2020). Within the same large cohort as herein, we compared various dietary patterns and their relationships with various sustainable indicators. Using a validated dietary index reflecting adherence to the new French food-based guidelines (Chaltiel et al., 2019), we recently showed that high adherence was associated with markedly lower environmental impacts compared to low-adherence (Kesse-Guyot et al., 290 2020), with a 50\% reduction in pReCiPe and a 46\% reduction in GHGE. A lower overall environmental 291 performance for the studied indicators than the EAT-Lancet diet was, though, observed (for a $2500 \mathrm{kcal} / \mathrm{d}$ 292 diet, data not shown). This seems somehow in accordance with a recent work by Springmann et al, indicating 293 a greater reduction in GHGEs with the global FBGDs than the national FBGDs (Springmann et al., 2020). 294 In contrast, a recent review focusing on analysis of sustainability of dietary guidelines for Americans 295 reported that healthy US dietary patterns may be responsible for similar or higher GHGe, energy and water 296 use compared to current US diets (Reinhardt et al., 2020). The review study also underlined, as expected, 297 that plant-based dietary guidelines may only contribute to limit environmental pressures related to food 298 systems. Consistently, the modelling study of Springmann et al., evaluating environmental and health values 
299 of food-based dietary guidelines, compared to WHO and Eat-Lancet diet, showed that most of the national

300 food-based dietary guidelines do not allow achieving health and environmental goals (Springmann et al., $3012020)$.

302 It is noteworthy that the pReCiPe distribution across ELD-I quintiles revealed that low environmental 303 impact was not systematically associated with healthy dietary patterns. Thus, while nutritionally healthy 304 diet and environment preservation are overall in alignment, these dimensions however may not always go 305 hand in hand. This observation seems in line with previous works showing that unhealthy foods, such as 306 sweet and fat food, may exhibit low environmental impacts (Clark et al., 2019; Perignon et al., 2017) and 307 observational studies showing that the lowest emitting diets are not systematically the most sustainable as 308 regards their nutritional values (Vieux et al., 2020). This is of great importance from a public health point 309 of view as it highlights the need of fostering both environment-friendly and healthy diets. It is also notable 310 that unsustainable diets (low ELD-I) were those the least expensive, raising the issue related to affordability 311 of sustainable and healthy diets for vulnerable population.

312 A global score such as the ELD-I score allows to consider recommendations as a whole as it integrates 313 interrelations between food groups, (Burggraf et al., 2018). Based on predefined cut-off values (Knuppel et 314 al., 2019),we developed a continuous index based on the overall consumption distributions to improve 315 power of discrimination of the score and smooth distribution. It has indeed been shown that dietary scores 316 based on binary scoring such as some Mediterranean diet scores led to little consideration of the variability 317 in food consumption (Burggraf et al., 2018).

318 Some limitations of the present work should be noted. First, our sample was not representative of the general 319 population as the NutriNet-Santé study included voluntary participants, limiting the external validation of 320 the results. Second, our life cycle assessment did not cover the stages posterior to food production. However, 321 production is one of the major drivers of environmental pressures within the food system, although food 322 loss and waste along the supply chain are substantial (Morone et al., 2019). Few accurate information 323 covering all the food chain exists especially for alternative production systems. Finally, we did not compute 324 indicators related to water use, biodiversity, excess nitrogen or soil quality as data were not available. 
325 Our study also presents major strengths that include the consideration of two different farming practices

326 (organic and conventional systems) allowing a more accurate environmental analysis. In addition, the three

327 computed environmental impacts reflect major environmental issues (Kramer et al., 2017). Furthermore, the

328 large sample size permitted the access to a large variety of dietary patterns.

329 This study documented that the planetary health diet as defined by the EAT-Lancet Commission (i.e. based

330 on a comprehensive review of the scientific literature) was associated with a higher nutritional quality and

331 lower environmental impacts in accordance with the objectives of the EAT-Lancet report. This definition

332 of a universal diet is crucial for aligning the health and environmental dimensions and allows comparable

333 assessments in different contexts. It should however be noted that in some cases, unhealthy diets may also

334 be linked to low environmental impacts arguing for dissemination of guidelines integrating both dimensions.

335 However, further work is needed to better test for the validation of the EAT-Lancet diet. Future optimization

336 models works to formulate adequate nutritional intakes with reduced environmental footprints and cultural

337 adaptation of the EAT-Lancet diet, as conducted only in Denmark, is also warranted (Lassen et al., 2020).

338 Relationships between the EAT-Lancet reference diet and various health outcomes should be evaluated in

339 different settings. In addition, as regards environmental pressures, the consideration of a larger number of

340 indicators (e.g. water use) while differentiating the type of farming system may be valuable. Finally,

341 prospective scenarios to assess feasibility would be informative.

\section{5. Acknowledgements}

343 The authors warmly thank all the volunteers of the NutriNet-Santé cohort.

344 We also thank Cédric Agaesse (dietitian); Younes Esseddik (IT manager), Thi Hong Van Duong, Régis 345 Gatibelza, Djamal Lamri, Jagatjit Mohinder and Aladi Timera (computer scientists); Julien Allegre, 346 Nathalie Arnault, Laurent Bourhis and Fabien Szabo de Edelenyi, PhD (supervisor) (data347 manager/statisticians) for their technical contribution to the NutriNet-Santé study.

348 Clinical Trial Registry: The study was registered at ClinicalTrials.gov (NCT03335644).

\section{Financial Support}


The NutriNet-Santé study was supported by the following public institutions : Ministère de la Santé, Santé

Publique France, Institut National de la Santé et de la Recherche Médicale (INSERM), Institut national de

recherche pour l'agriculture, l'alimentation et l'environnement (INRAe), Conservatoire National des Arts

et Métiers (CNAM) and Université Sorbonne Paris Nord. Researchers were independent from funders.

Funders had no role in the study design, the collection, analysis, and interpretation of data, the writing of

the report, and the decision to submit the article for publication.

\section{Data sharing statement}

Data of the study are protected under the protection of health data regulation set by the French National

Commission for Information Technology and Liberties (Commission Nationale de l'Informatique et des

Libertés, CNIL). The data are available upon request to the study's operational manager, Nathalie Pecollo

(n.pecollo@eren.smbh.univ-paris13.fr), for review by the steering committee of the NutriNet-Santé study.

\section{References}

Aleksandrowicz, L., Green, R., Joy, E.J., Smith, P., Haines, A., 2016. The Impacts of Dietary Change on Greenhouse Gas Emissions, Land Use, Water Use, and Health: A Systematic Review. PLoS.One. 11, e0165797. https://doi.org/10.1371/journal.pone.0165797

Aleksandrowicz, Lukasz, Green, R., Joy, E.J.M., Smith, P., Haines, A., 2016. The Impacts of Dietary Change on Greenhouse Gas Emissions, Land Use, Water Use, and Health: A Systematic Review. PLoS ONE 11, e0165797. https://doi.org/10.1371/journal.pone.0165797

Armah, S.M., Carriquiry, A., Sullivan, D., Cook, J.D., Reddy, M.B., 2013. A complete diet-based algorithm for predicting nonheme iron absorption in adults. J. Nutr. 143, 1136-1140. https://doi.org/10.3945/jn.112.169904

Auestad, N., Fulgoni, V.L., III, 2015. What current literature tells us about sustainable diets: emerging research linking dietary patterns, environmental sustainability, and economics. Adv.Nutr. 6, 1936. https://doi.org/10.3945/an.114.005694

Baudry, J., Debrauwer, L., Durand, G., Limon, G., Delcambre, A., Vidal, R., Taupier-Letage, B., DruesnePecollo, N., Galan, P., Hercberg, S., Lairon, D., Cravedi, J.-P., Kesse-Guyot, E., 2018. Urinary pesticide concentrations in French adults with low and high organic food consumption: results from the general population-based NutriNet-Santé. J Expo Sci Environ Epidemiol. https://doi.org/10.1038/s41370-018-0062-9

Baudry, J., Méjean, C., Allès, B., Péneau, S., Touvier, M., Hercberg, S., Lairon, D., Galan, P., KesseGuyot, E., 2015. Contribution of Organic Food to the Diet in a Large Sample of French Adults (the NutriNet-Santé Cohort Study). Nutrients 7, 8615-8632. https://doi.org/10.3390/nu7105417

Baudry, J., Pointereau, P., Seconda, L., Vidal, R., Taupier-Letage, B., Langevin, B., Allès, B., Galan, P., Hercberg, S., Amiot, M.-J., Boizot-Szantai, C., Hamza, O., Cravedi, J.-P., Debrauwer, L., Soler, L.-G., Lairon, D., Kesse-Guyot, E., 2019. Improvement of diet sustainability with increased level of organic food in the diet: findings from the BioNutriNet cohort. Am J Clin Nutr 109, 11731188. https://doi.org/10.1093/ajen/nqy361 
386

387

388

389

390

391

392

393

394

395

396

397

398

399

400

401

402

403

404

405

406

407

408

409

410

411

412

413

414

415

416

417

418

419

420

421

422

423

424

425

426

427

428

429

430

431

432

433

434

Blackstone, N.T., Conrad, Z., 2020. Comparing the Recommended Eating Patterns of the EAT-Lancet Commission and Dietary Guidelines for Americans: Implications for Sustainable Nutrition. Curr Dev Nutr 4, nzaa015. https://doi.org/10.1093/cdn/nzaa015

Burggraf, C., Teuber, R., Brosig, S., Meier, T., 2018. Review of a priori dietary quality indices in relation to their construction criteria. Nutr. Rev. 76, 747-764. https://doi.org/10.1093/nutrit/nuy027

Burlingame, B., Dernini, S., 2011. Sustainable diets: the Mediterranean diet as an example. Public Health Nutr 14, 2285-2287. https://doi.org/10.1017/S1368980011002527

Castañé, S., Antón, A., 2017. Assessment of the nutritional quality and environmental impact of two food diets: A Mediterranean and a vegan diet. Journal of Cleaner Production 167, 929-937. https://doi.org/10.1016/j.jclepro.2017.04.121

Chai, B.C., van der Voort, J.R., Grofelnik, K., Eliasdottir, H.G., Klöss, I., Perez-Cueto, F.J.A., 2019. Which Diet Has the Least Environmental Impact on Our Planet? A Systematic Review of Vegan, Vegetarian and Omnivorous Diets. Sustainability 11, 4110. https://doi.org/10.3390/su11154110

Chaltiel, D., Adjibade, M., Deschamps, V., Touvier, M., Hercberg, S., Julia, C., Kesse-Guyot, E., 2019. Programme National Nutrition Santé - guidelines score 2 (PNNS-GS2): development and validation of a diet quality score reflecting the 2017 French dietary guidelines. British Journal of Nutrition 122, 331-342. https://doi.org/10.1017/S0007114519001181

Clark, M., Hill, J., Tilman, D., 2018. The Diet, Health, and Environment Trilemma. Annual Review of Environment and Resources 43, 109-134. https://doi.org/10.1146/annurev-environ-102017025957

Clark, M.A., Springmann, M., Hill, J., Tilman, D., 2019. Multiple health and environmental impacts of foods. PNAS 116, 23357-23362. https://doi.org/10.1073/pnas.1906908116

Clune, S., Crossi,E., Verghese, K., 2017. Systematic review of greenhouse gas emissions for different fresh food categories. J Clean Prod 140 (Part 2), 766-783.

Définition - Unité de consommation | Insee [WWW Document], n.d. URL https://www.insee.fr/fr/metadonnees/definition/c1802 (accessed 5.22.20).

Gavelle, E. de, Huneau, J.-F., Mariotti, F., 2018. Patterns of Protein Food Intake Are Associated with Nutrient Adequacy in the General French Adult Population. Nutrients 10. https://doi.org/10.3390/nu10020226

Gazan, R., Brouzes, C.M.C., Vieux, F., Maillot, M., Lluch, A., Darmon, N., 2018. Mathematical Optimization to Explore Tomorrow's Sustainable Diets: A Narrative Review. Adv Nutr 9, 602616. https://doi.org/10.1093/advances/nmy049

GBD 2017 Diet Collaborators, 2019. Health effects of dietary risks in 195 countries, 1990-2017: a systematic analysis for the Global Burden of Disease Study 2017. Lancet 393, 1958-1972. https://doi.org/10.1016/S0140-6736(19)30041-8

Gerber, P.H., Steinfeld, H., Henderson, B., Mottet, A., Opio, C., Dijkman, J., Falcucci, A., Tempio, G., 2013. Tackling Climate Change through Livestock - A global assessment of emissions and mitigation opportunities. Food and Agriculture Organization of the United Nations (FAO), Rome.

Gomiero, T., Pimentel, D., Paoletti, M.G., 2011. Environmental Impact of Different Agricultural Management Practices: Conventional vs. Organic Agriculture. Critical Reviews in Plant Sciences 30, 95-124. https://doi.org/10.1080/07352689.2011.554355

González-García, S., Green, R.F., Scheelbeek, P.F., Harris, F., Dangour, A.D., 2020. Dietary recommendations in Spain -affordability and environmental sustainability? Journal of Cleaner Production 254, 120125. https://doi.org/10.1016/j.jclepro.2020.120125

Grosso, G., Fresán, U., Bes-Rastrollo, M., Marventano, S., Galvano, F., 2020. Environmental Impact of Dietary Choices: Role of the Mediterranean and Other Dietary Patterns in an Italian Cohort. Int J Environ Res Public Health 17. https://doi.org/10.3390/ijerph17051468

Hagstromer, M., Oja, P., Sjostrom, M., 2006. The International Physical Activity Questionnaire (IPAQ): a study of concurrent and construct validity. Public Health Nutr. 9, 755-762. 
Hallström, E., Carlsson-Kanyama, A., Börjesson, P., 2015. Environmental impact of dietary change: a systematic review. Journal of Cleaner Production 91, 1-11. https://doi.org/10.1016/j.jclepro.2014.12.008

Hercberg, S., Castetbon, K., Czernichow, S., Malon, A., Mejean, C., Kesse, E., Touvier, M., Galan, P., 2010. The Nutrinet-Sante Study: a web-based prospective study on the relationship between nutrition and health and determinants of dietary patterns and nutritional status. BMC Public Health 10, 242. https://doi.org/10.1186/1471-2458-10-242

Hirvonen, K., Bai, Y., Headey, D., Masters, W.A., 2020. Affordability of the EAT-Lancet reference diet: a global analysis. Lancet Glob Health 8, e59-e66. https://doi.org/10.1016/S2214-109X(19)30447-4

Hunt, J.R., Zito, C.A., Johnson, L.K., 2009. Body iron excretion by healthy men and women. Am J Clin Nutr 89, 1792-1798. https://doi.org/10.3945/ajen.2009.27439

Jones, A.D., Hoey, L., Blesh, J., Miller, L., Green, A., Shapiro, L.F., 2016. A Systematic Review of the Measurement of Sustainable Diets. Advances in Nutrition: An International Review Journal 7, 641-664. https://doi.org/10.3945/an.115.011015

Kantar Worldpanel, n.d. Consumer Panels [WWW Document]. URL https://www.kantarworldpanel.com/global (accessed 7.4.17).

Kesse-Guyot, E., Assmann, K., Andreeva, V., Castetbon, K., Méjean, C., Touvier, M., Salanave, B., Deschamps, V., Péneau, S., Fezeu, L., Julia, C., Allès, B., Galan, P., Hercberg, S., 2016. Lessons Learned From Methodological Validation Research in E-Epidemiology. JMIR Public Health Surveill 18, e160. https://doi.org/10.2196/publichealth.5880

Kesse-Guyot, E., Castetbon, K., Touvier, M., Hercberg, S., Galan, P., 2010. Relative validity and reproducibility of a food frequency questionnaire designed for French adults. Ann. Nutr. Metab. 57, 153-162. https://doi.org/10.1159/000321680

Kesse-Guyot, E., Chaltiel, D., Wang, J., Pointereau, P., Langevin, B., Allès, B., Rebouillat, P., Lairon, D., Vidal, R., Mariotti, F., Egnell, M., Touvier, M., Julia, C., Baudry, J., Hercberg, S., 2020.

Sustainability analysis of French dietary guidelines using multiple criteria. Nature Sustainability 1-9. https://doi.org/10.1038/s41893-020-0495-8

Knuppel, A., Papier, K., Key, T.J., Travis, R.C., 2019. EAT-Lancet score and major health outcomes: the EPIC-Oxford study. The Lancet 394, 213-214. https://doi.org/10.1016/S0140-6736(19)31236-X

Kramer, G.F., Tyszler, M., Veer, P.V., Blonk, H., 2017. Decreasing the overall environmental impact of the Dutch diet: how to find healthy and sustainable diets with limited changes. Public Health Nutr 20, 1699-1709. https://doi.org/10.1017/S1368980017000349

Lacour, C., Seconda, L., Allès, B., Hercberg, S., Langevin, B., Pointereau, P., Lairon, D., Baudry, J., Kesse-Guyot, E., 2018. Environmental Impacts of Plant-Based Diets: How Does Organic Food Consumption Contribute to Environmental Sustainability? Front Nutr 5, 8. https://doi.org/10.3389/fnut.2018.00008

Laroche, P.C.S.J., Schulp, C.J.E., Kastner, T., Verburg, P.H., 2020. Telecoupled environmental impacts of current and alternative Western diets. Global Environmental Change 62, 102066. https://doi.org/10.1016/j.gloenvcha.2020.102066

Lassen, A.D., Christensen, L.M., Trolle, E., 2020. Development of a Danish Adapted Healthy Plant-Based Diet Based on the EAT-Lancet Reference Diet. Nutrients 12. https://doi.org/10.3390/nu12030738

Mariotti, F., 2019. Animal and Plant Protein Sources and Cardiometabolic Health. Adv Nutr 10, S351S366. https://doi.org/10.1093/advances/nmy110

Mertens, E., Kuijsten, A., van Zanten, H.HE., Kaptijn, G., Dofková, M., Mistura, L., D’Addezio, L., Turrini, A., Dubuisson, C., Havard, S., Trolle, E., Geleijnse, J.M., Veer, P. van 't, 2019. Dietary choices and environmental impact in four European countries. Journal of Cleaner Production 237, 117827. https://doi.org/10.1016/j.jclepro.2019.117827

Mie, A., Kesse-Guyot, E., Rembialkowska, E., Grandjean, P., Gunnarsson, S., 2016. Human health implications of organic food and organic agriculture.

Miller, L.V., Krebs, N.F., Hambidge, K.M., 2007. A mathematical model of zinc absorption in humans as a function of dietary zinc and phytate. J. Nutr. 137, 135-141. https://doi.org/10.1093/jn/137.1.135 
Morone, P., Koutinas, A., Gathergood, N., Arshadi, M., Matharu, A., 2019. Food waste: Challenges and opportunities for enhancing the emerging bio-economy. Journal of Cleaner Production 221, 10 16. https://doi.org/10.1016/j.jclepro.2019.02.258

Perignon, M., Vieux, F., Soler, L.G., Masset, G., Darmon, N., 2017. Improving diet sustainability through evolution of food choices: review of epidemiological studies on the environmental impact of diets. Nutr.Rev. 75, 2-17. https://doi.org/10.1093/nutrit/nuw043

Pointereau, P., Langevin, B., Gimaret, M., 2012. DIALECTE, a comprehensive and quick tool to assess the agro-environmental performance of farms. Presented at the 10th European IFSA Symposium: Producing and reproducing farming systems.

Reinhardt, S.L., Boehm, R., Blackstone, N.T., El-Abbadi, N.H., McNally Brandow, J.S., Taylor, S.F., DeLonge, M.S., 2020. Systematic Review of Dietary Patterns and Sustainability in the United States. Adv Nutr. https://doi.org/10.1093/advances/nmaa026

Ridoutt, B.G., Hendrie, G.A., Noakes, M., 2017. Dietary Strategies to Reduce Environmental Impact: A Critical Review of the Evidence Base. Adv Nutr 8, 933-946. https://doi.org/10.3945/an.117.016691

Seconda, L., Baudry, J., Alles, B., Boizot-Szantai, C., Soler, L.-G., Galan, P., Hercberg, S., Langevin, B., Lairon, D., Pointereau, P., Kesse-Guyot, E., 2018. Comparing nutritional, economic, and environmental performances of diets according to their levels of greenhouse gas emissions. Clim. Change 148, 155-172. https://doi.org/10.1007/s10584-018-2195-1

Springmann, M., Clark, M., Mason-D'Croz, D., Wiebe, K., Bodirsky, B.L., Lassaletta, L., de Vries, W., Vermeulen, S.J., Herrero, M., Carlson, K.M., Jonell, M., Troell, M., DeClerck, F., Gordon, L.J., Zurayk, R., Scarborough, P., Rayner, M., Loken, B., Fanzo, J., Godfray, H.C.J., Tilman, D., Rockström, J., Willett, W., 2018. Options for keeping the food system within environmental limits. Nature 562, 519-525. https://doi.org/10.1038/s41586-018-0594-0

Springmann, M., Spajic, L., Clark, M.A., Poore, J., Herforth, A., Webb, P., Rayner, M., Scarborough, P., 2020. The healthiness and sustainability of national and global food based dietary guidelines: modelling study. BMJ 370, m2322. https://doi.org/10.1136/bmj.m2322

Tuomisto, H.L., Hodge, I.D., Riordan, P., Macdonald, D.W., 2012. Does organic farming reduce environmental impacts?--a meta-analysis of European research. J Environ.Manage. 112, 309-320. https://doi.org/10.1016/j.jenvman.2012.08.018

van Dooren, C., 2018. A Review of the Use of Linear Programming to Optimize Diets, Nutritiously, Economically and Environmentally. Front Nutr 5, 48. https://doi.org/10.3389/fnut.2018.00048

van Dooren, C., Marinussen, M., Blonk, H., Aiking, H., Vellinga, P., 2014. Exploring dietary guidelines based on ecological and nutritional values: A comparison of six dietary patterns. Food Policy 44, 36-46. https://doi.org/10.1016/j.foodpol.2013.11.002

Veronese, N., Solmi, M., Caruso, M.G., Giannelli, G., Osella, A.R., Evangelou, E., Maggi, S., Fontana, L., Stubbs, B., Tzoulaki, I., 2018. Dietary fiber and health outcomes: an umbrella review of systematic reviews and meta-analyses. Am. J. Clin. Nutr. 107, 436-444. https://doi.org/10.1093/ajcn/nqx082

Vieux, F., Privet, L., Soler, L.G., Irz, X., Ferrari, M., Sette, S., Raulio, S., Tapanainen, H., Hoffmann, R., Surry, Y., Pulkkinen, H., Darmon, N., 2020. More sustainable European diets based on selfselection do not require exclusion of entire categories of food. Journal of Cleaner Production 248, 119298. https://doi.org/10.1016/j.jclepro.2019.119298

Willett, W., Rockström, J., Loken, B., Springmann, M., Lang, T., Vermeulen, S., Garnett, T., Tilman, D., DeClerck, F., Wood, A., Jonell, M., Clark, M., Gordon, L.J., Fanzo, J., Hawkes, C., Zurayk, R., Rivera, J.A., De Vries, W., Majele Sibanda, L., Afshin, A., Chaudhary, A., Herrero, M., Agustina, R., Branca, F., Lartey, A., Fan, S., Crona, B., Fox, E., Bignet, V., Troell, M., Lindahl, T., Singh, S., Cornell, S.E., Srinath Reddy, K., Narain, S., Nishtar, S., Murray, C.J.L., 2019. Food in the Anthropocene: the EAT-Lancet Commission on healthy diets from sustainable food systems. Lancet 393, 447-492. https://doi.org/10.1016/S0140-6736(18)31788-4 
536 Zagmutt, F.J., Pouzou, J.G., Costard, S., 2020. The EAT-Lancet Commission's Dietary Composition May 537 Not Prevent Noncommunicable Disease Mortality. J. Nutr. https://doi.org/10.1093/jn/nxaa020 


\section{Tables}

Table 1: Cut-off for each component of the EAT-Lancet Diet Index ${ }^{1}$

\begin{tabular}{llr}
\hline Food component & Subcomponent & Cut-off \\
\hline Whole grains & & $\leq 464 \mathrm{~g} / \mathrm{d}$ \\
Potatoes and tuber & & $\leq 100 \mathrm{~g} / \mathrm{d}$ \\
Vegetables & $\geq 200 \mathrm{~g} / \mathrm{d}$ \\
Fruits & & $\geq 100 \mathrm{~g} / \mathrm{d}$ \\
Dairy foods & & $\leq 500 \mathrm{~g} / \mathrm{d}$ \\
Proteins sources & & \\
& & $\leq 28 \mathrm{~g} / \mathrm{d}$ \\
& Beef, lamb, pork & $\leq 58 \mathrm{~g} / \mathrm{d}$ \\
& Chicken and poultry & $\leq 25 \mathrm{~g} / \mathrm{d}$ \\
& Eggs & $\leq 100 \mathrm{~g} / \mathrm{d}$ \\
& Fish & $\leq 100 \mathrm{~g} / \mathrm{d}$ \\
& Legumes & $\geq 25 \mathrm{~g} / \mathrm{d}$
\end{tabular}

Added fats

$\begin{array}{ll}\text { Saturated oil } & \leq 11.8 \mathrm{~g} / \mathrm{d} \\ \text { Unsaturated oils } & \leq 80 \mathrm{~g} / \mathrm{d}\end{array}$

Added sugars $\quad$ All sweet $\quad$ Added sugar $\leq 31 \mathrm{~g} / \mathrm{d}$

${ }^{1}$ Cut-offs for a $2500 \mathrm{kcal}$ diet based on Knuppel et. al (Knuppel et al., 2019). 
Table 2: Characteristics of the sample across ELD-I quintiles, $n=29,210$, NutriNet-Santé 1

\begin{tabular}{|c|c|c|c|c|c|c|}
\hline & $\mathbf{Q}_{1}$ & $\mathbf{Q}_{2}$ & $\mathbf{Q}_{3}$ & $\mathbf{Q}_{4}$ & $Q_{5}$ & $\mathbf{p}^{2}$ \\
\hline Cut-off & $\leq 4.35$ & ]4.35-21.46] & ]21.46-37.67] & ]37.67-59.74] & $>59.74$ & \\
\hline \%men & 62.2 & 50.91 & 42.03 & 38.13 & 34.51 & $<.0001$ \\
\hline Age, $y$ & $50.54(14.08)$ & $52.12(14.15)$ & $53.93(13.82)$ & $55.16(13.63)$ & $56.03(13.54)$ & $<.0001$ \\
\hline Education (\%) & & & & & & $<.0001$ \\
\hline$<$ High-school diploma & 58.14 & 54.15 & 58.13 & 60.27 & 68.76 & \\
\hline High school diploma & 16.6 & 18.35 & 13.74 & 15.91 & 12.1 & \\
\hline Postgraduate & 25.26 & 27.5 & 28.13 & 23.82 & 19.14 & \\
\hline Occupation (\%) & & & & & & $<.0001$ \\
\hline Unemployed & 6.44 & 2.34 & 3.04 & 4.02 & 3.84 & \\
\hline Retired & 15.31 & 27.89 & 30.56 & 35.25 & 36.32 & \\
\hline Employee, manual worker & 41.03 & 28.06 & 28.06 & 26.19 & 26.36 & \\
\hline Intermediate profession & 16.19 & 15.94 & 12.86 & 12.07 & 13.98 & \\
\hline $\begin{array}{l}\text { Managerial staff and } \\
\text { intellectual profession }\end{array}$ & 8.55 & 9.85 & 11.42 & 8.93 & 7.04 & \\
\hline Never employed & 7.97 & 10.25 & 10.43 & 10.47 & 7.44 & \\
\hline Self-employed, farmer & 4.52 & 5.67 & 3.65 & 3.07 & 5.01 & \\
\hline Monthly income (\%) & & & & & & $<.0001$ \\
\hline Unwilling to answer & 6.23 & 4.98 & 7.25 & 8.24 & 9.96 & \\
\hline$<1,200 €$ & 28.64 & 23.2 & 19.41 & 26.86 & 24.88 & \\
\hline $1,200-1,800 €$ & 30.99 & 29.13 & 29.46 & 26.22 & 25.24 & \\
\hline $1,800-2,700 €$ & 23.07 & 23.94 & 26.44 & 22.63 & 26.04 & \\
\hline$>2,700 €$ & 11.07 & 18.75 & 17.44 & 16.06 & 13.88 & \\
\hline Physical activity level (\%) & & & & & & $<.0001$ \\
\hline Missing data & 19.76 & 12.3 & 12.23 & 10.46 & 16.49 & \\
\hline Low & 26.74 & 24.15 & 19.94 & 20.44 & 10.41 & \\
\hline Moderate & 26.34 & 30.88 & 33.2 & 33.83 & 29 & \\
\hline High & 27.15 & 32.66 & 34.63 & 35.26 & 44.1 & \\
\hline Tobacco status (\%) & & & & & & $<.0001$ \\
\hline Never smoker & 43.39 & 45.42 & 48.94 & 48.06 & 55.1 & \\
\hline Former smoker & 42.72 & 39.1 & 38.92 & 43.68 & 38.09 & \\
\hline Current smoker & 13.88 & 15.49 & 12.14 & 8.26 & 6.81 & \\
\hline Cost of the $\operatorname{diet}(€ / d)$ & $7.72(2.92)$ & $7.38(2.65)$ & $7.43(2.73)$ & $7.48(2.73)$ & $8.53(3.66)$ & $<.0001$ \\
\hline Body mass index $\left(\mathrm{kg} / \mathrm{m}^{2}\right)$ & $25.12(4.95)$ & $24.62(4.62)$ & $24.32(4.65)$ & $23.82(4.44)$ & $23.13(4.21)$ & $<.0001$ \\
\hline
\end{tabular}


Table 3: Nutritional characteristics of the sample across EAT-Lancet Diet Index quintiles,

\section{n= 29,210, NutriNet-Santé ${ }^{1}$}

\begin{tabular}{|c|c|c|c|c|c|c|}
\hline & $\mathbf{Q}_{1}$ & $\mathbf{Q}_{2}$ & $\mathbf{Q}_{3}$ & $\mathbf{Q}_{4}$ & Q5 & $\mathbf{P}^{2}$ \\
\hline Energy intake (kcal/d) & $2099(694)$ & $2030(624)$ & $1994(606)$ & $1947(589)$ & $1935(612)$ & $<.0001$ \\
\hline PANDiet (/100) & $59.47(6.20)$ & $62.54(6.39)$ & $64.81(7.01)$ & $67.50(7.51)$ & $70.55(7.15)$ & $<.0001$ \\
\hline Health score (/9) & $0.91(0.22)$ & $0.98(0.21)$ & $1.06(0.22)$ & $1.14(0.22)$ & $1.41(0.38)$ & $<.0001$ \\
\hline Alcohol $(\mathrm{g} / \mathrm{d})$ & $9.06(13.23)$ & $9.55(13.06)$ & $9.47(13.44)$ & $8.27(11.45)$ & $6.23(10.90)$ & $<.0001$ \\
\hline Proportion of organic food ${ }^{3}$ & $0.17(0.19)$ & $0.23(0.22)$ & $0.28(0.25)$ & $0.35(0.28)$ & $0.45(0.32)$ & $<.0001$ \\
\hline$\%$ Carbohydrates & $35.37(6.98)$ & $38.39(6.46)$ & $39.65(6.54)$ & $40.80(6.83)$ & $43.89(8.00)$ & $<.0001$ \\
\hline$\%$ Lipids $^{4}$ & $42.96(6.19)$ & $41.89(6.25)$ & $41.30(6.63)$ & $40.91(7.18)$ & $39.05(8.50)$ & $<.0001$ \\
\hline$\% \mathrm{SFA}^{4}$ & $17.15(3.13)$ & $16.16(3.12)$ & $15.31(3.15)$ & $14.13(3.09)$ & $11.87(3.22)$ & $<.0001$ \\
\hline$\%$ MUFA $^{4}$ & $16.48(3.31)$ & $16.30(3.52)$ & $16.29(3.84)$ & $16.59(4.31)$ & $16.32(5.17)$ & $<.0001$ \\
\hline$\%$ PUFA $^{4}$ & $6.10(1.80)$ & $6.33(1.99)$ & $6.64(2.23)$ & $7.19(2.61)$ & $7.94(3.28)$ & $<.0001$ \\
\hline$\%$ Proteins 4 & $21.35(3.72)$ & $19.37(3.02)$ & $18.67(3.09)$ & $17.88(3.23)$ & $16.57(3.53)$ & $<.0001$ \\
\hline Proportion of plant proteins & $0.22(0.07)$ & $0.28(0.07)$ & $0.32(0.09)$ & $0.37(0.12)$ & $0.48(0.19)$ & $<.0001$ \\
\hline Fibers $(\mathrm{g} / \mathrm{d})$ & $16.03(5.17)$ & $19.38(4.47)$ & $22.25(4.84)$ & $25.74(5.36)$ & $33.36(9.40)$ & $<.0001$ \\
\hline Sodium $(\mathrm{mg} / \mathrm{d})$ & $2717(574)$ & $2621(473)$ & $2563(483)$ & $2430(478)$ & $2181(558)$ & $<.0001$ \\
\hline Vitamin B12 $(\mu \mathrm{g} / \mathrm{d})$ & $8.17(9.28)$ & $6.84(3.36)$ & $6.40(3.02)$ & $5.97(3.04)$ & $5.15(3.07)$ & $<.0001$ \\
\hline Vitamin C (mg/d) & $108.00(58.10)$ & $127.08(58.28)$ & $142.37(62.11)$ & $161.19(63.51)$ & $223.82(105.87)$ & $<.0001$ \\
\hline Vitamin B9 $(\mu \mathrm{g} / \mathrm{d})$ & $333.10(108.71)$ & $366.88(86.55)$ & $400.76(92.15)$ & $443.67(99.22)$ & $552.95(180.94)$ & $<.0001$ \\
\hline Vitamin $E(\mathrm{mg} / \mathrm{d})$ & $11.80(4.58)$ & $13.06(4.54)$ & $14.15(4.62)$ & $15.53(4.86)$ & $18.34(5.67)$ & $<.0001$ \\
\hline Calcium (mg/d) & $1069(323)$ & $1119(316)$ & $1142(319)$ & $1138(327)$ & $1107(331)$ & $<.0001$ \\
\hline Iron & $14.33(3.79)$ & $14.52(3.15)$ & $15.26(3.47)$ & $16.05(3.68)$ & $17.26(4.10)$ & $<.0001$ \\
\hline Heme-iron & $2.17(1.70)$ & $1.49(0.66)$ & $1.23(0.59)$ & $1.02(0.60)$ & $0.74(0.60)$ & $<.0001$ \\
\hline Zinc & $14.25(3.25)$ & $12.89(2.24)$ & $12.58(2.21)$ & $12.30(2.26)$ & $11.78(2.32)$ & $<.0001$ \\
\hline
\end{tabular}

Abbreviations: MUFA: monounsaturated fatty acids, PUFA; polyunsaturated fatty acids, Q: quintiles;

SFA: saturated fatty acidsx

${ }^{1}$ Values are means (standard deviations)

${ }^{2} \mathrm{P}$ for trend across quintiles of PNNS-GS2 assessed by linear contrast

${ }^{3}$ Proportion of weight excluding water

${ }^{4}$ As percent of alcohol-free energy intake 
Table 4: Environmental indicators across EAT-Lancet Diet Index quintiles, n= 29,210,

\section{NutriNet-Santé ${ }^{1}$}

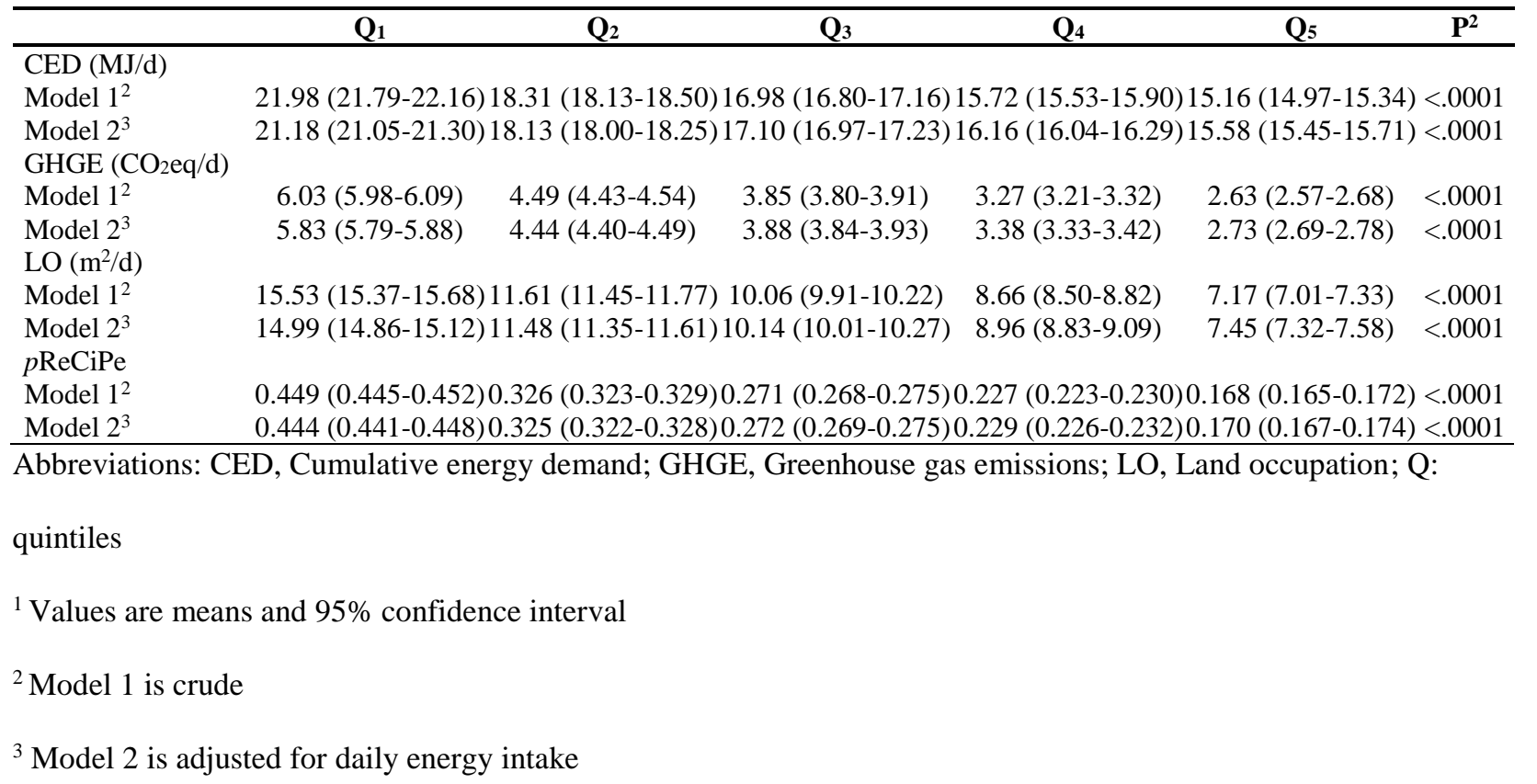



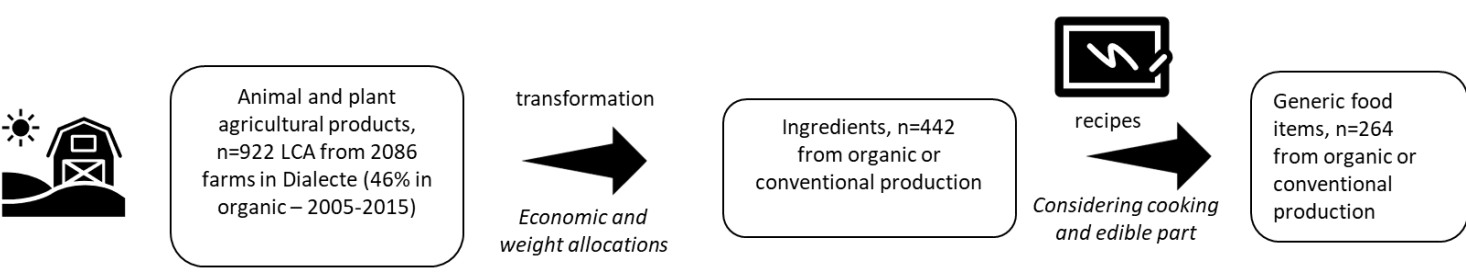

Figure 1: Steps for calculating the environmental indicators 


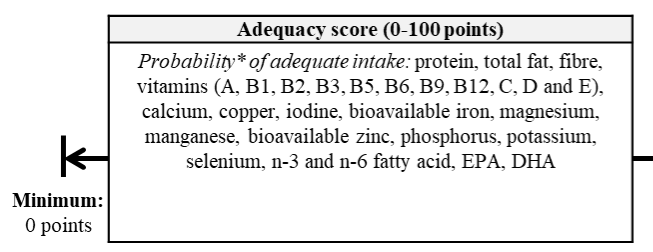

\begin{tabular}{|l|}
\hline \multicolumn{1}{|c|}{ Moderation score (0-100 points) } \\
\hline $\begin{array}{l}\text { Probability* of non-excessive intake } \text { : protein, total } \\
\text { fat, sugars, saturated fatty acids, cholesterol, and } \\
\text { sodium }\end{array}$ \\
\hline $\begin{array}{c}\text { Pimimuationof the moderation score if intake }> \\
\text { published upper limits for: retinol, vitamins } \mathrm{B} 3, \mathrm{~B} 6, \\
\mathrm{~B} 9, \mathrm{D} \text { and } \mathrm{E}, \text { calcium, copper, magnesium, iodine, } \\
\text { selenium, and zinc }\end{array}$ \\
\hline
\end{tabular}

Figure 2: Computation of the PANDiet score

Abbreviations: DHA, docosahexaenoic acid; EPA, eicosapentaenoic acid.

F (ranged from 0 to 1 , where 1 represents a $100 \%$ probability that the usual intake was adequate):

'Probnorm' function in SAS, $\mathrm{y}$ is the mean intake, $\mathrm{SD}_{\mathrm{y}}$ the day-to-day variability of intake, $\mathrm{n}$ the number of dietary record days, $\mathrm{r}$ the nutrient reference value, $\mathrm{SD}_{\mathrm{r}}$ the interindividual variability. 


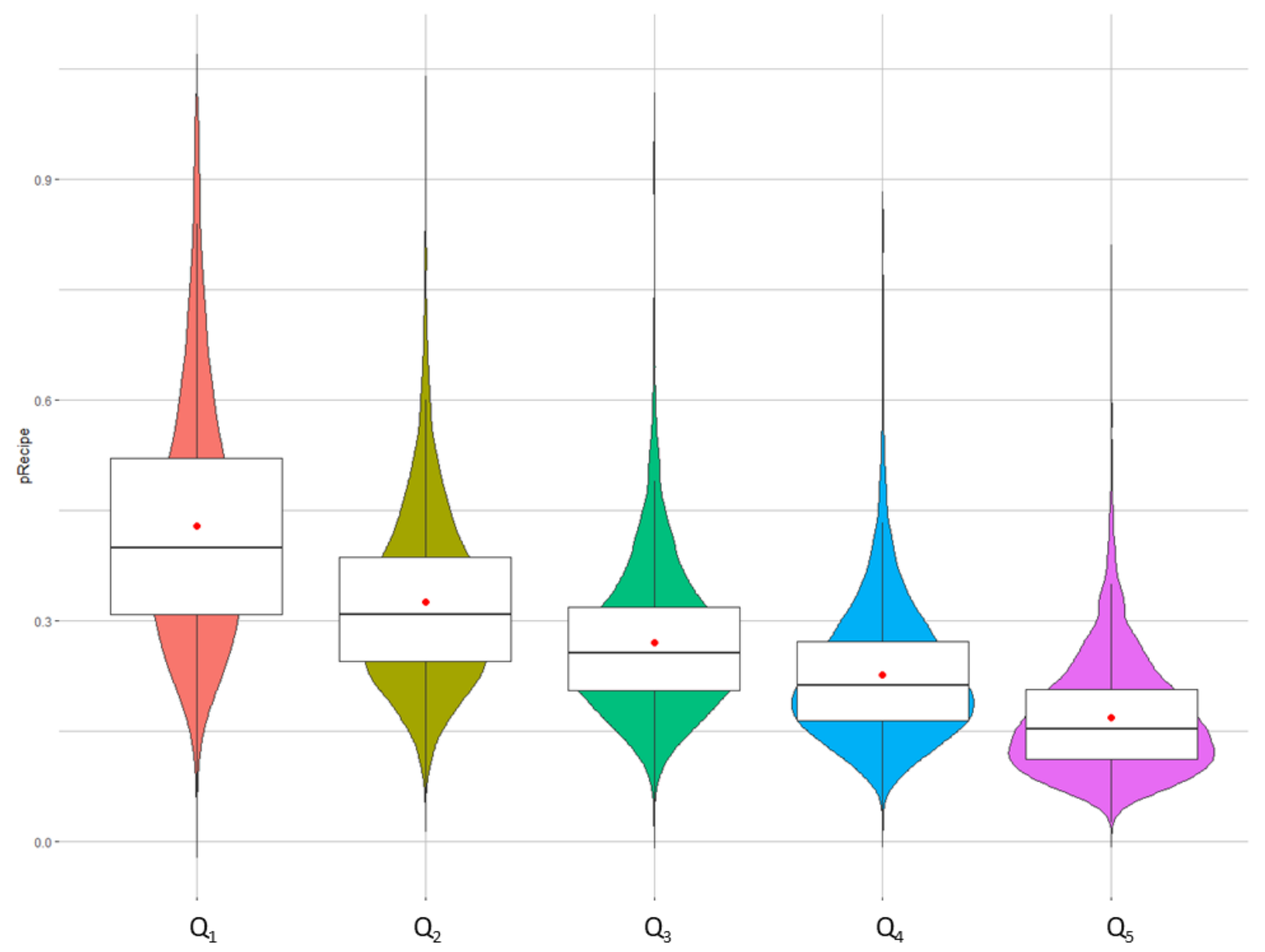

Figure 3: $p$ Recipe distribution across ELD-I quintiles ${ }^{1}$

${ }^{1}$ Unadjusted distribution is presented. 


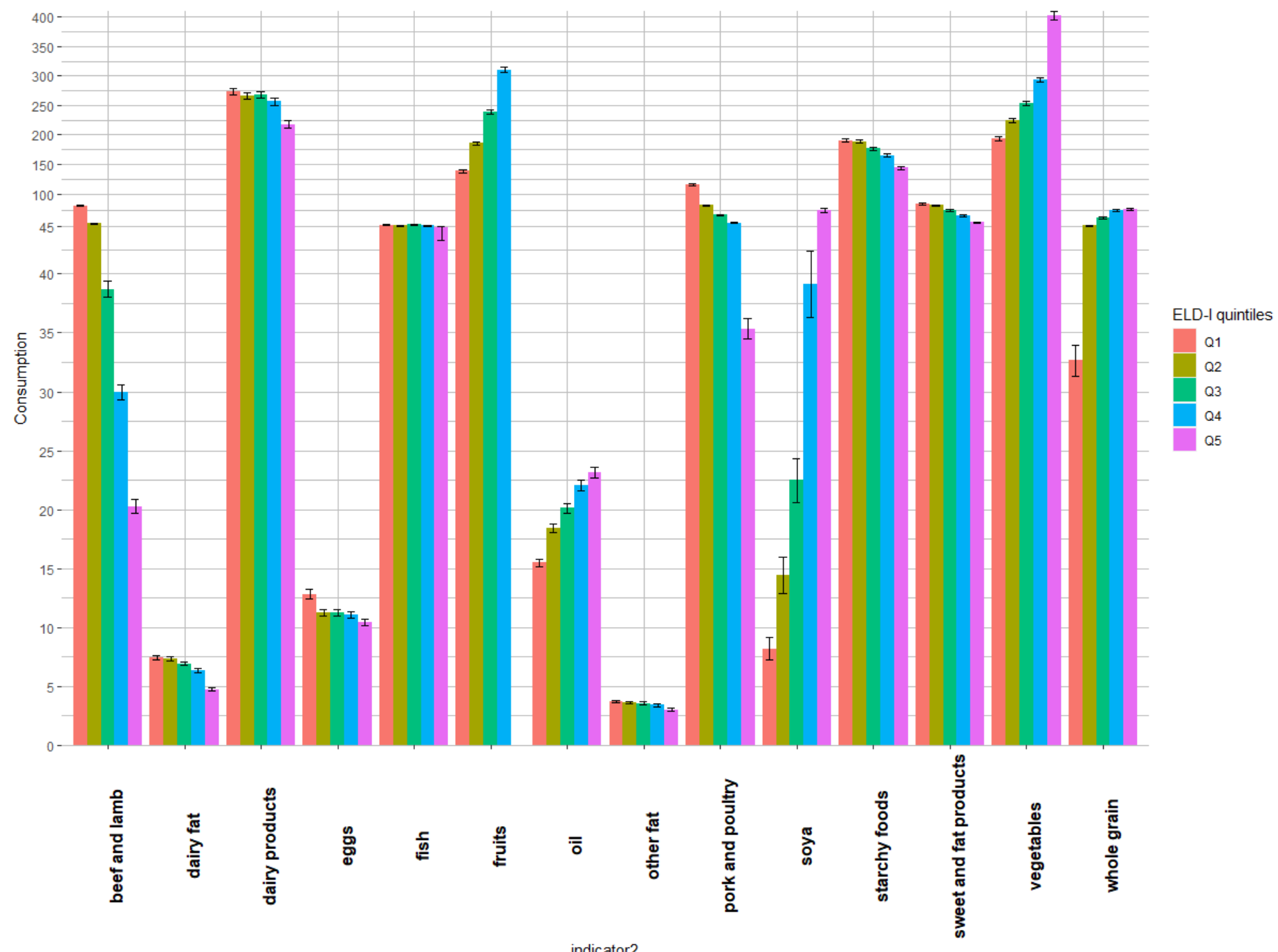

Figure 4: Food consumption (intake in g/d) across ELD-I quintiles ${ }^{1}$

Abbreviations: Q, quintile

${ }^{1}$ Values are unadjusted means and 95\% confidence interval, all P-values for trend were $<0.0001$. 